\title{
Molecular Recognition by Pillar[5]arenes: Balance Between Hy- drophobic and Electrostatic Interactions
}

\author{
B. Gómez-González ${ }^{1}$, L. García-Río ${ }^{1, *}$, N. Basilioº ${ }^{2}$ J.C. Mejuto ${ }^{3, *}$ and J. Simal-Gandara ${ }^{4}$
}

1 Departamento de Química Física, Facultade de Química, Universidade de Santiago de Compostela, 15782 Santiago, Spain; gomezgonzalezborja@gmail.com (B.G.G.); luis.garcia@usc.es (L.G.R.)

2 Laboratório Associado para a Química Verde (LAQV), Rede de Química e Tecnologia (REQUIMTE), Departamento de Química, Faculdade de Ciências e Tecnologia, Universidade NOVA de Lisboa, 2829-516 Caparica, Portugal; nuno.basilio@fct.unl.pt (N.B.)

3 Department of Physical Chemistry, Faculty of Science, University of Vigo, Ourense Campus, E32004 Ourense, Spain; xmejuto@uvigo.es (J.C.M.)

4 Nutrition and Bromatology Group, Analytical and Food Chemistry Department, Faculty of Food Science and Technology, University of Vigo, Ourense Campus, E32004 Ourense, Spain; jsimal@uvigo.es (J.S.G.)

* Correspondence: luis.garcia@usc.es (L.G.R.) \& xmejuto@uvigo.es (J.C.M.)

\begin{abstract}
The formation of inclusion complexes between alkylsulfonate guests and a cationic pillar[5]arene receptor in water was investigated by NMR and ITC techniques. The results show the formation of host-guest complexes stabilized by electrostatic interactions and hydrophobics effects with binding constants of up to $10^{7} \mathrm{M}^{-1}$ for the guest with higher hydrophobic character. Structurally, the alkyl chain of the guest is included in the hydrophobic aromatic cavity of the macrocycle while the sulfonate groups are hold in the multicationic portal by ionic interactions.
\end{abstract}

Keywords: Pillararene; host:guest; supramolecular; hydrophobic; ITC; NMR

\section{Introduction}

Supramolecular chemistry has attracted a considerable amount of attention from chemists, material scientists and biologists, looking to exploit noncovalent interactions, such as hydrogen-bonding interaction, $\pi-\pi$ stacking interaction, electrostatic interaction, van der Waals force, and hydrophobic/hydrophilic attraction, to develop and explain systems of increasing complexity (bottom-up approach) [1-3]. During the past decades, considerable efforts have been paid to develop numerous supramolecular systems and to investigate their applications in catalysis, functional materials, electronic devices, sensors, nanomedicine, and so on [4-6]. Among these applications, nanomedicine presents promising potentials form modernizing traditional biomedical practices, and in this context, the creation of supramolecular materials within nanometer range become a hot research topic. The construction of new supramolecular structures offers the potential for novel diagnostic and therapeutic applications in nanomedicine [7]. The specific biomedical applications include drug delivery, gene delivery, drug/gene codelivery, bioimaging, as well as photodynamic therapy [8]. Noncovalent interactions present several advantages in comparison to covalent ones: (i) easy and facile approach for building supramolecular structures avoiding synthetic processes [9]. (ii) Supramolecular methods are cost-effective and environmentally friendly. (iii) Supramolecular materials consist of components connected by non-covalent interactions and experiencing spontaneous assembly or disassembly processes[10-12]. (iv) Formation of supramolecular materials is reversible being capable of recycled and self-repaired from external mechanical damage. (v) Supramolecular materials have the ability of responding to external stimuli being able to rearrange their structures or morphologies toward more stable states. This adaptive capability can be utilized for the design and fabrication of stimuli-responsive functional materials [13-16]. (vi) Supramolecular chemistry provides a possibility of manipulating molecules or 
supramolecular building blocks at a molecular level, allowing the "bottom-up" method to control de sizes and morphologies of the resulting materials, providing a variety of novel diagnostic and therapeutic platforms toward applications in nanomedicine.

Among various noncovalent interactions under the definition of supramolecular chemistry, host:guest interactions based on macrocyclic molecules is a very important phenomenon that has been extensively investigated. Through such host:guest inclusion, two or more chemical moieties can be integrated together in a facile and reversible manner, providing vast possibilities for the construction of novel supramolecular structures. Molecular recognition that involves host:guest interactions plays a vital role in life-sustaining biological processes [17,18]. Macrocyclic compounds have been extensively used and intensively investigated as prime host receptors with high affinity and selectivity for complementary small guest molecules or ions. Examples of macrocycles include cryptands [19], crown ethers [20-22], cyclophanes [23], cyclopeptides [24-26], cyclodextrins [27-29], resorcinarenes [30], cucurbit[n]urils [31-34], calix[n]arenes [35-38], and pillar[n]arenes.[39] These macrocyclic molecules are regarded as the hosts, possessing the cavities to encapsulate the guest. Usually, external property of the host molecules favors the interaction with surrounding solvent, while the internal features of their cavities facilitate the guest inclusion via hydrophobic interactions, hydrogen-bonding interactions, electrostatic interaction, specific molecular shape or size matching, etc. The most common case is to encapsulate hydrophobic guest molecules into hydrophobic cavities of macrocyclic molecules in aqueous solution. Such host:guest inclusion has relatively high stability, providing a reliable and robust connection for the fabrication of supramolecular systems in water.

Pillar[n]arenes are one of the most recent family of macrocyclic hosts used in supramolecular chemistry [40]. Pillararenes bring together some interesting characteristic of other host systems in a single molecular structure such a highly symmetrical pillar-shaped structure which are similar in many respects to that of highly symmetrical cucurbiturils, a $\pi$-rich aromatic cavity, also found in calixarenes, and several hydroxyl moieties on both rims, a feature shared with the highly functionalized cyclodextrins. Substituents on both rims of pillararenes affect their physical properties such as solubility, conformational and host:guest properties. Pillar[n]arenes are useful scaffolds for the design of various interesting supramolecular systems including liquid crystalline materials [41], cyclic dimers [42,43], chemosensors [44], supramolecular polymers [45], drug delivery systems [46], trans-membrane channels [47], cell glue [48], selective adsorption of porous materials [49], molecular recognition [50] and nanotubes [51].
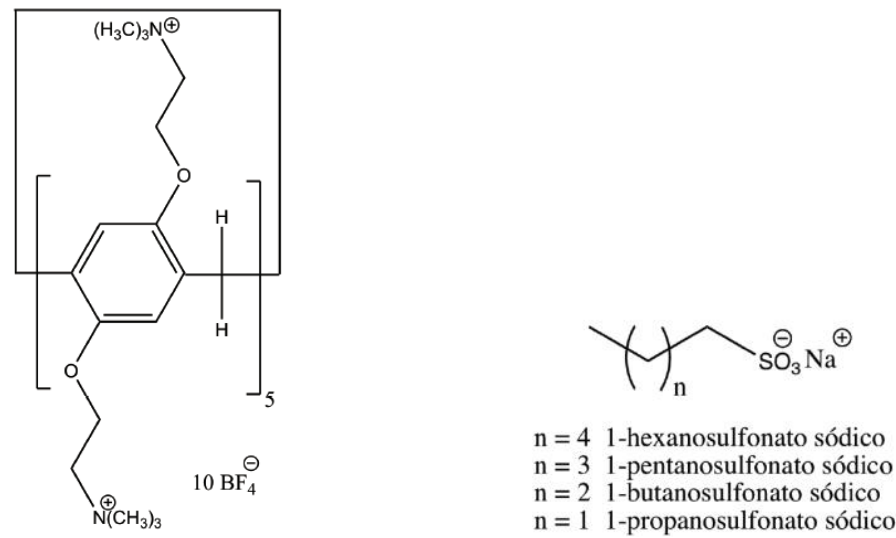

Scheme 1. TMAP5

Pillararenes bearing ionic moieties on all of the substituents are water-soluble (see Scheme 1), and their complexation with a variety of different guest molecules[52,53] as well as their potential application in catalysis[54-56], sensing $[57,58]$ and gene nanocarriers 
[59] has been investigated in aqueous media. When oppositely charged ionic molecules were evaluated as guest molecules for host systems of this type, cationic/anionic electrostatic interactions made a significant contribution to the stabilization of the resulting complexes.

Pillararenes-based host-guest systems comprising amphiphilic guests offer interesting strategies for the development of novel stimuli-responsive drug-delivery systems [60]. Furthermore, charged amphiphilic compounds, such as phospholipids, are ubiquitous in biological systems. In this context, fundamental studies on the interaction between charged pillararene receptors and model amphiphilic compounds are of utmost importance for envisaged pharmaceutical applications concerning these macrocycles. In this work, we report a structural and thermodynamic study on the host-guest complexes formed between negatively charged alkylsulfonates and a cationic pillar[5]arene (see Scheme 1).

\section{Materials and Methods}

\subsection{Materials}

Reagents of maximum purity were purchased from Sigma-Aldrich and used without further purification. The cationic water-soluble pillar[5]arene was synthesized according to a literature procedure (see Supporting Information Section) [61]. The exchange of the $\mathrm{Br}^{-}$counterion by $\mathrm{BF}_{4}^{-}$was achieved by the following procedure: $\mathrm{AgBF}_{4}$ was slowly added in small portions to a solution of $\mathrm{H}$ with $\mathrm{Br}^{-}$as counterion $(1.17 \mathrm{~g}, 0.514 \mathrm{mmol})$ in Milli-Q water under stirring at room temperature. A thin grayish precipitate was obtained. The suspension was separated by centrifugation and the supernatant collected was filtered through a $0.45 \mu \mathrm{m}$ filter. After removal of the solvent, a yellowish solid was obtained (1.15g, 96\%). ${ }^{1} \mathrm{H}$ NMR (D2O, $\left.300 \mathrm{MHz}\right): \delta=6.89$ (s, $\left.10 \mathrm{H}\right) ; \delta=4.36(\mathrm{~s}, 20 \mathrm{H}) ; \delta=3.91(\mathrm{~s}, 10 \mathrm{H})$; $\delta=3.72(\mathrm{~s}, 20 \mathrm{H}) ; \delta=3.19(\mathrm{~s}, 90 \mathrm{H}) ;{ }^{13} \mathrm{C}$ NMR $\left(\mathrm{D}_{2} \mathrm{O}, 75 \mathrm{MHz}\right): \delta=149.2(\mathrm{C}, 10 \mathrm{C}) ; \delta=129.8(\mathrm{C}, 10 \mathrm{C})$; $\delta=115.9(\mathrm{CH}, 10 \mathrm{C}) ; \delta=64.8\left(\mathrm{CH}_{2}, 10 \mathrm{C}\right) ; \delta=62.3\left(\mathrm{CH}_{2}, 10 \mathrm{C}\right) ; \delta=53.7\left(\mathrm{CH}_{3}, 30 \mathrm{C}\right) ; \delta=29.3\left(\mathrm{CH}_{2}\right.$, $5 \mathrm{C})$; MS (ESI): $\mathrm{m} / \mathrm{z}$ calcd for [TMAP5 $\left.{ }^{10+} .9 \mathrm{BF}_{4}\right]^{-2+} 2253.4$; found 2253.2; calcd for $\left[\mathrm{TMAP}^{10^{+}} .8 \mathrm{BF}_{4}\right]^{2+}$ 1083.3; found 1083.1. The pillararene was also analyzed by thermal gravimetric analysis to assess volatile content.

\subsection{Microcalorimetry}

Microcalorimetric titrations were performed by using an isothermal titration microcalorimeter (VP-ITC) from Microcal Co. (Northamptoh, MA) at atmospheric pressure and $25^{\circ} \mathrm{C}$. In each run, a solution of guest in a $0.270 \mathrm{~mL}$ syringe was sequentially injected with stirring at $459 \mathrm{rpm}$ into a solution of host in the sample cell (1.459mL volume). Each solution was degassed and thermostatted by using a ThermoVac accessory before titration. In each titration the reference cell was filled with the same sample as in the sample cell. In all experiments the first injection was discarded to eliminate diffusion effects on the calorimetric cell of material from the syringe. The number of injections, their volume and the spacing time between each one were varied according to the experiment. Binding constants were calculated form the titration curve by using the AFFINImeter software.

\subsection{NMR spectrometry}

NMR experiments were conducted at $25^{\circ} \mathrm{C}$ on a Bruker NEO $17.6 \mathrm{~T}$ spectrometer (proton resonance $750 \mathrm{MHz}$ ), equipped with a ${ }^{1} \mathrm{H} /{ }^{13} \mathrm{C} /{ }^{15} \mathrm{~N}$ triple resonance PA-TXI probe with deuterium lock channel and shielded PFG z-gradient. The spectrometer control software was TopSpin 4.0. The chemical shifts reported are referenced to the lock deuterium solvent. Spectra were processed and analyzed with Mestrenova software v14.0 (Mestrelab Inc.). The $1 \mathrm{D}{ }^{1} \mathrm{H}$ spectrum was measured with 128 scans, a relaxation delay of $\mathrm{d} 12 \mathrm{~s}$ and a FID acquisition time (aq) of $2.75 \mathrm{~s}$. The FID was acquired with $64 \mathrm{k}$ complex data points 
and was processed with zero-filling and Fourier Transformation (FT) to obtain a spectrum with $131 \mathrm{k}$ data points. The total measurement time was $\sim 10 \mathrm{~min}$.

A two-dimensional 2D COSY spectrum magnitude mode was measured (pulse sequence "cosygpppqf" of Bruker library). The relaxation delay ( $\left.\mathrm{d}_{1}\right)$ and the FID acquisition time (at) were 2 and $0.172 \mathrm{~s}$, respectively. The spectrum was measured with 8 scans. The number of points in the direct and indirect dimensions was $4 \mathrm{k}$ and 160, respectively. The spectrum was processed with apodization with a sine-bell function in both dimensions and represented in the magnitude mode. The total measurement time was $\sim 48 \mathrm{~min}$.

A two-dimensional 2D HSQC multiplicity edited $1 \mathrm{H}-13 \mathrm{C}$ spectrum was measured (pulse sequence "hsqcedetgpsisp2.4" of the Bruker library). The spectrum includes adiabatic inversion pulses in ${ }^{13} \mathrm{C}$ and suppression of COSY type artefacts. The INEPTs transfers were optimized for a nominal value of ${ }^{1} \mathrm{~J}_{\mathrm{H}}$ of $145 \mathrm{~Hz}$. The delay for multiplicity selection was set to $1 /\left(2 \cdot{ }^{1} \mathrm{JH}_{\mathrm{CH}}\right)$ to detect with the same sign signals of $\mathrm{CH}_{3}$ and $\mathrm{CH}$ groups and with opposite phase $\mathrm{CH}_{2}$ groups. The relaxation delay $\left(\mathrm{d}_{1}\right)$ and the FID acquisition time (at) were 1.6 and $0.112 \mathrm{~s}$, respectively. The spectrum was acquired with 2048 and 160 complex points in the $\mathrm{t} 2$ and $\mathrm{t} 1$ dimensions, respectively. The number of scans per $\mathrm{t} 1$ increment was 8 and the total measurement time was $\sim 1 \mathrm{~h} 15 \mathrm{~min}$.

\section{Results}

The hydrophobic cavity allied with the presence of five positive charges on each rim makes pillararene a good receptor for amphiphilic anionic guests. The complexation of the negatively charged alkylsulfonates $(\mathrm{G})$ by pillararene $(\mathrm{H})$ was studied by different techniques.

\subsection{NMR evidence of n-octylsulfonate complexation by pillararene}

NMR spectroscopy is a powerful tool and has been widely used to determine the structures of macrocycles complexes by analyzing the complexation induced shifts. The ${ }^{1} \mathrm{H}$ NMR spectra of octylsulfonate upon mixing in different proportions with pillararene can be observed in Figure 1.
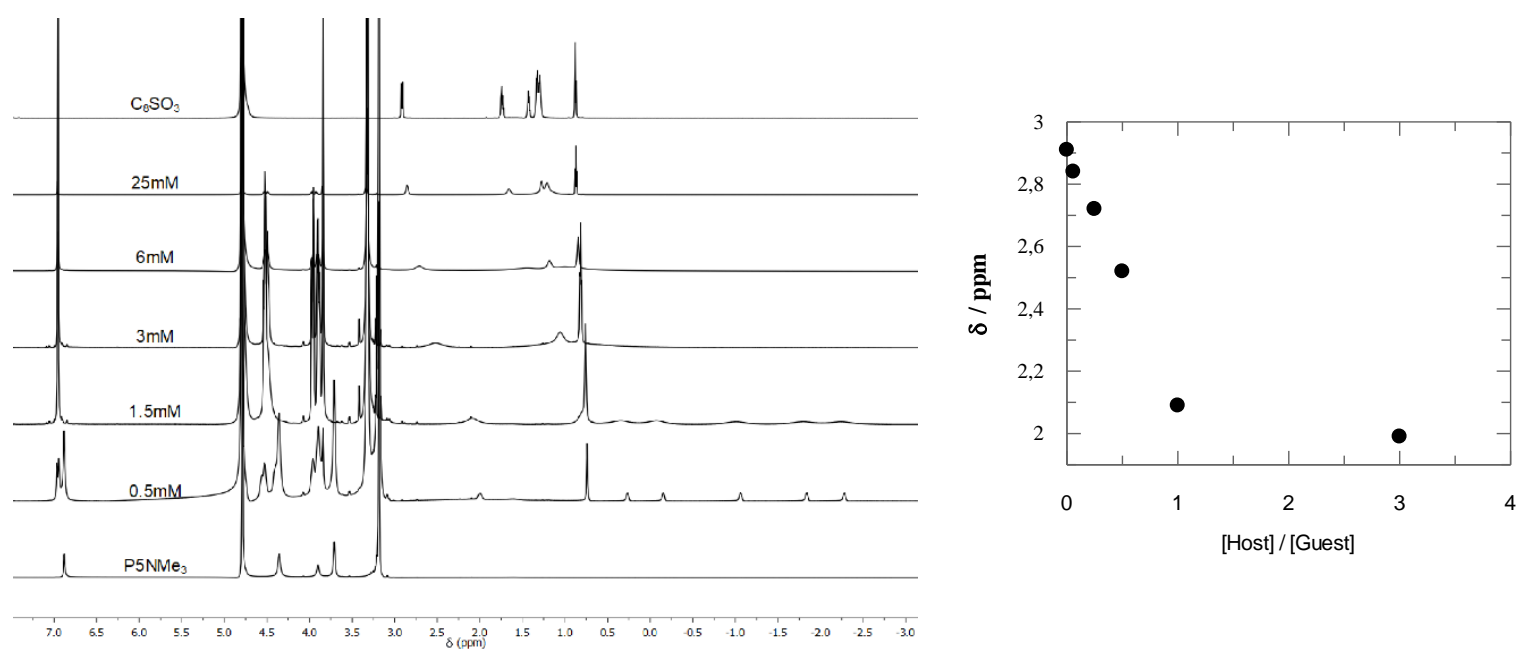

Figure 1. (left) ${ }^{1} \mathrm{H}$ NMR spectra in $\mathrm{D}_{2} \mathrm{O}$ at $25^{\circ} \mathrm{C}$ for pillararene $(1.5 \mathrm{mM})$; octylsulfonate $(1.5 \mathrm{mM})$ and mixtures of both with constant concentration of pillararene $(1.5 \mathrm{mM})$ and different concentrations of octylsulfonate. (right) Chemical shifts for hydrogen atoms in alpha position to the sulfonate group in octylsulfonate in the presence of increasing concentrations of host. 
All protons of octylsulfonate appear upfield-shifted with respect to the free guest upon addition of pillararene, indicating that an inclusion complex was formed. These results indicate that octylsulfonate is incorporated into the magnetic shielding region of the pillararene aromatic cavity with the sulfonate group pointing towards the trimethylammonium groups of the host. Moreover the host proton signals are also affected by complexation due to the asymmetric structure of the guest and the manner in which it is inserted into the host cavity [52]. To determine the binding stoichiometry of the host:guest complex, considering that fast exchange on the NMR chemical shift timescale was observed for this complex, an NMR titration at constant host concentration, was carried out. Figure 1-right shows that the magnitude of the upfield shift for guest hydrogen atoms increases upon gradual increase of the [host]/[guest] ratio, reaching a plateau for values higher than 1, indicating a 1:1 stoichiometry for the inclusion complex.

Detailed analysis of spectrum for [Pillararene] $=1.5 \mathrm{mM}$ and [octylsulfonate] $=0.50 \mathrm{mM}$ (Figure 1-left) reveals that the signal corresponding to the methylene groups in positions C4-C7 of octylsulfonate splits into different signals, allowing a clear characterization of the inclusion complex. Figure 2 shows the HSQC and COSY spectra allowing the assignment of all signals in the NMR spectrum.
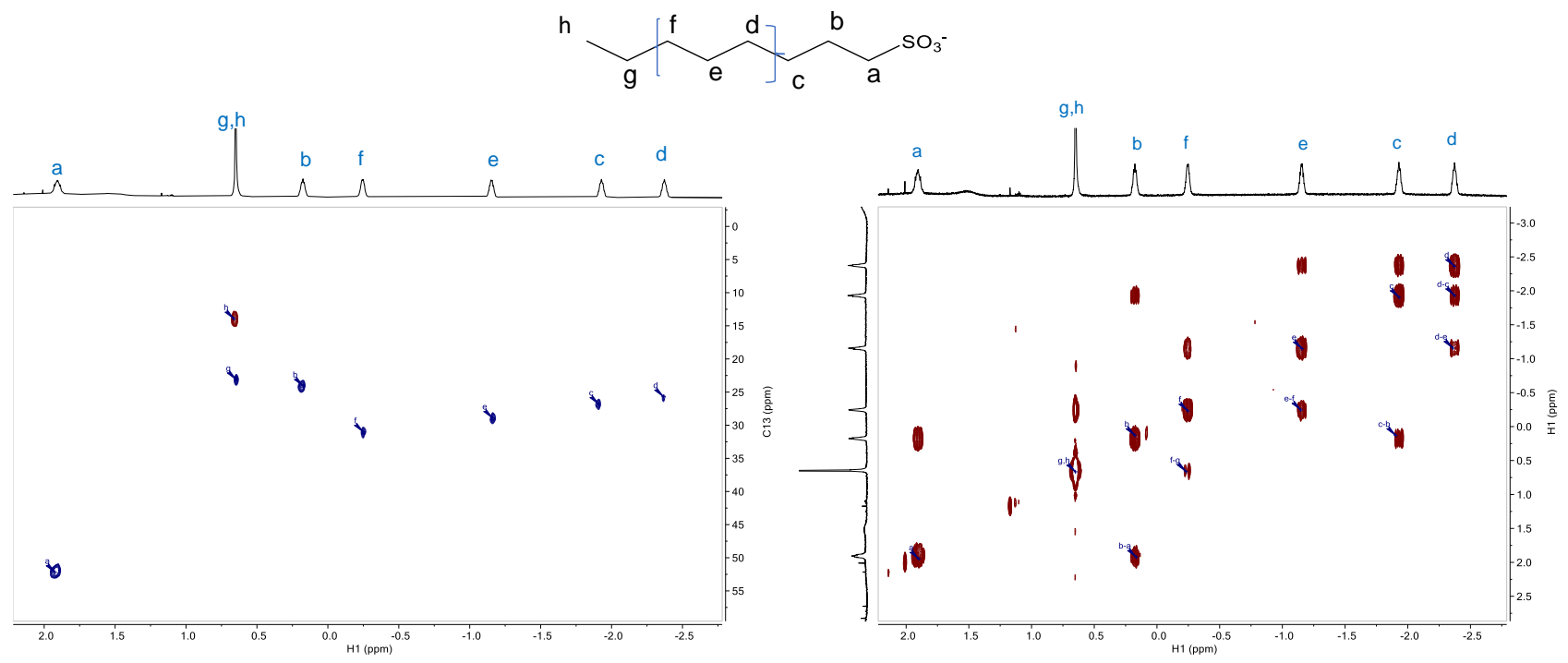

Figure 2. HSQC (left) and COSY (right) spectra for a mixture of $1.5 \mathrm{mM}$ of Pillararene and $0.5 \mathrm{mM}$ of octylsulfonate in $\mathrm{D}_{2} \mathrm{O}$ a $25^{\circ} \mathrm{C}$.

Labels for octylsulfonate hydrogen atoms are according to the picture showed in the figure.

Assignment of NMR signals allow us to quantify the magnitude of the complexation induced upfield effect for each hydrogen atom in octylsulfonate (results showed in Table 1). We refer to a complexation induced chemical shift as the difference between the chemical shift observed for the guest free and complexated, $\Delta \delta=\delta$ free- $\delta$ bound. Magnitude of $\Delta \delta$ is dependent on the hydrogen atom position along the alkyl chain of octylsulfonate. It is remarkable the very large magnitude of the upfield effects with values larger than $\Delta \delta=3 \mathrm{ppm}$ for some central chain nuclei. Hydrogen atoms Hc and Hd show the large @® values allowing to propose a structure for the host:guest complex as shown in Figure 3. Hydrogen atoms in position $c$ and $d$ are located inside the aromatic region of the pillararene allowing the large $\Delta \delta$ values, $\Delta \delta>3 \mathrm{ppm}$. Hydrogens at position e should be just below this region but close to the aromatic groups $(\Delta \delta=2.3 \mathrm{ppm})$. It is remarkable that hydrogen atoms at positions $g$ and $h(\Delta \delta<1 \mathrm{ppm})$, as well as in alpha position to the sulfonate group, are clearly located outside the aromatic region. 
Table 1. Magnitude of the complexation induced chemical shifts (๑๑) for host:guest complexes between pillararene and different alkylsulfonates.

\begin{tabular}{|c|c|c|c|c|c|c|c|c|}
\hline \multicolumn{9}{|c|}{$\Delta \delta(\mathrm{ppm})$} \\
\hline & Ha & $\mathrm{Hb}$ & Hc & $\mathrm{Hd}$ & $\mathrm{He}$ & Hf & $\mathrm{Hg}$ & $\mathrm{Hh}$ \\
\hline $\mathrm{C}_{8} \mathrm{SO}_{3}{ }^{-}$ & 0.91 & 1.48 & 3.27 & 3.58 & 2.37 & 1.46 & 0.56 & 0.14 \\
\hline $\mathrm{C}_{6} \mathrm{SO}_{3}{ }^{-}$ & 1.11 & 1.72 & 3.7 & 3.8 & 2.02 & 0.98 & & \\
\hline $\mathrm{C}_{5} \mathrm{SO}_{3}{ }^{-}$ & 1.24 & 1.78 & 3.84 & 3.85 & 1.76 & & & \\
\hline $\mathrm{C}_{4} \mathrm{SO}_{3}{ }^{-}$ & 1.24 & 1.84 & 3.33 & 2.81 & & & & \\
\hline $\mathrm{C}_{3} \mathrm{SO}_{3}{ }_{3}^{-}$ & 0.94 & 1.2 & 2.16 & & & & & \\
\hline
\end{tabular}
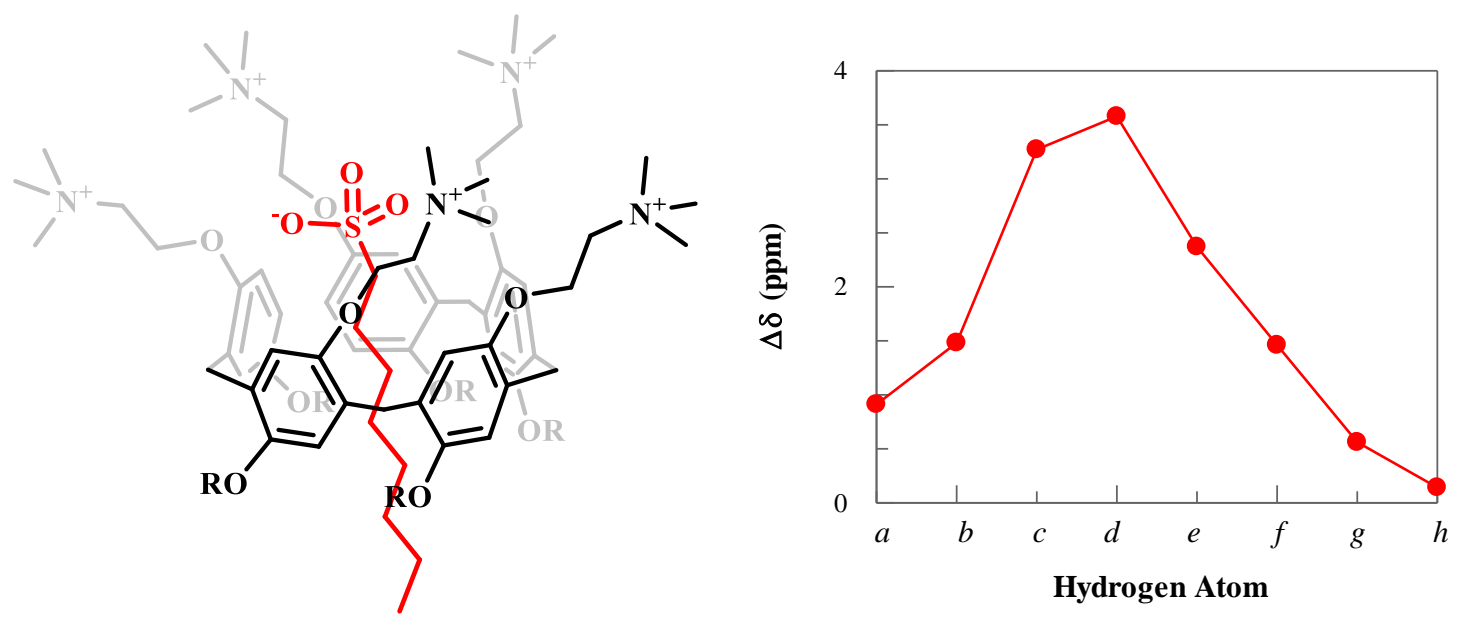

R: $\mathrm{CH}_{2} \mathrm{CH}_{2} \mathrm{~N}^{+}\left(\mathrm{CH}_{3}\right)_{3}$

Figure 3. (left) Plot of the magnitude of complexation induced chemical shift, $\Delta \delta$, as a function of the hydrogen atom position (starting at the sulfonate group). (Right) Schematic picture of the host:guest complex showing hydrogens Hc and Hd fully incorporated into the aromatic region of the host. Form simplicity only two trimethylammonium groups of pillararene are shown.

Similar experiments were conducted for for shorter chain alkylsulfonates with 3 to 6 carbon atoms (see Table 1) revealing that hydrogen atoms in positions Hc and Hd show the large upfield effects confirming that these atoms are clearly included inside the pillararene cavity. The complexation picture shows the sulfonate aligned with the trimethylammonium head groups of the receptor in such a way that electrostatic interaction should be the major driving force for complexation. It is remarkable that $\Delta \delta$ values are also dependent on the nature of the alkylsulfonate (see Figure 4). In fact, Ha hydrogen atoms show the large upfield effect for alkylsulfonates with 4 and 5 carbon atoms, meanwhile alkyl sulfonates with 3 and 8 carbon atoms present the smaller values. On the other hand, hydrogens $\mathrm{Hc}_{c}$ show the large upfield effect for $\mathrm{C}_{5} \mathrm{SO}_{3}{ }^{-}$and $\mathrm{C}_{6} \mathrm{SO}_{3}{ }^{-}$, and hydrogens $\mathrm{Hb}$ show the large $\Delta \delta$ for $\mathrm{C}_{4} \mathrm{SO}_{3}{ }^{-}$and $\mathrm{C}_{5} \mathrm{SO}_{3}{ }^{-}$. More clearly, Figure 4-left shows 
that the magnitude of $\Delta \delta$ is strongly dependent on the number of carbon atoms in the alkylsulfonate for hydrogens $\mathrm{Hc}>\mathrm{Hb}>\mathrm{Ha}$, being an indicative of different degree of penetration into the pillararene cavity. Figure 4 -rigth represents normalized $\Delta \delta_{\text {corr }}$ by subtracting the values corresponding to hydrogens Ha. The normalized values are directly comparable and indicate that $\mathrm{Hc}$ hydrogens are much closer to the cavity than $\mathrm{Hb}$ and that an optimal degree of penetration is reached for 5 atoms of carbon. Alkylsulfonates with 3 and 4 carbon atoms can form external complexes where the carbon atoms do not fit neatly together. This causes that the magnitude of $\Delta \delta_{\text {corr }}$ does not reach an optimal value. Likewise, it is observed that for octylsulfonate, the Hc hydrogens present a lower inclusion than for the 5 carbon atom homologue. This behavior may be due to a hydrophobic push up effect that compels the sulfonate group towards a plane superior to the portal of the pillararene in order to accommodate more methylene groups inside the cavity. At the same time, the possibility that the hydrophobic effect induces a greater degree of folding of the alkyl chain in order to maximize the number of carbon atoms that can be included in the cavity should be considered.
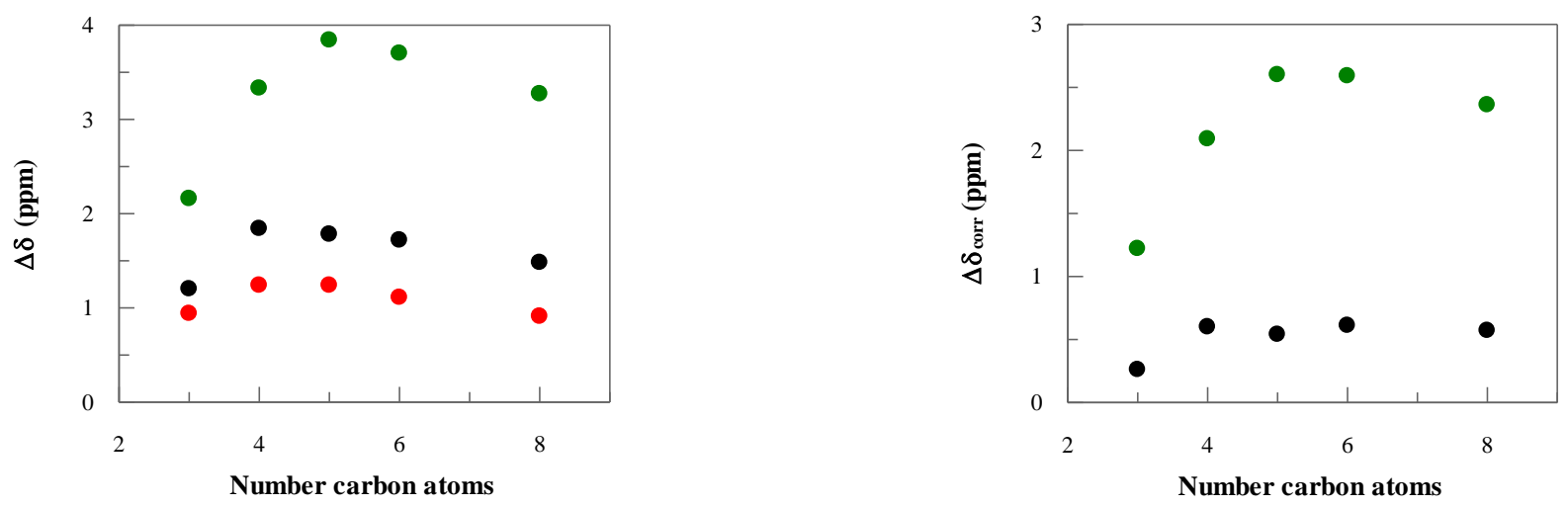

Figure 4. (left) Influence of the number of carbon atoms in the alkyl chain of alkylsulfonate on the chemical induced upfield effect, $\Delta \delta:(\bullet) \mathrm{Ha} ;(\bullet) \mathrm{Hb}$ and $(\bullet) \mathrm{Hc}$. (Right) Values of upfield effect for hydrogen atoms in positions $(\bullet) \mathrm{Hb}$ and $(\bullet)$ Hc after correction by ufpfield effect of hydrogens Ha.

These results indicate that location of the sulfonate group should be dependent on the number or carbon atoms, being closer to the positive portal of the pillararene for $\mathrm{C}_{5} \mathrm{SO}_{3}$ and $\mathrm{C}_{4} \mathrm{SO}_{3}$. This behavior can be observed for hydrogen atoms in positions $\mathrm{Hb}$ and $\mathrm{Hc}$, being a clear evidence of different degree of guest penetration into the host cavity and, consequently, ruling out the electrostatic attraction as the only interaction stabilizing the host:guest complex.

\subsection{Calorimetric tritrations for alikylsulfonate recognition by pillararene}

To quantitatively assess the complexation of pillararene with each guest, as well as the exact binding stoichiometry, isothermal titration calorimetry was performed at $25^{\circ} \mathrm{C}$ under neutral conditions. It is worth noting that each calorimetric titration was performed by the consecutive addition of the guest to the receptor host in the sample cell. As shown in Figure 5, each titration of butylsulfonate into the sample cell containing pillar[5]arene (see supporting information section for other alkylsulfonates) gave an apparent reaction heat caused by the formation of the inclusion complex. The titration data are well fitted by the "one set of binding sites" model to give both the binding constant $(\mathrm{K})$ and the thermodynamic parameters (see Table 2). 


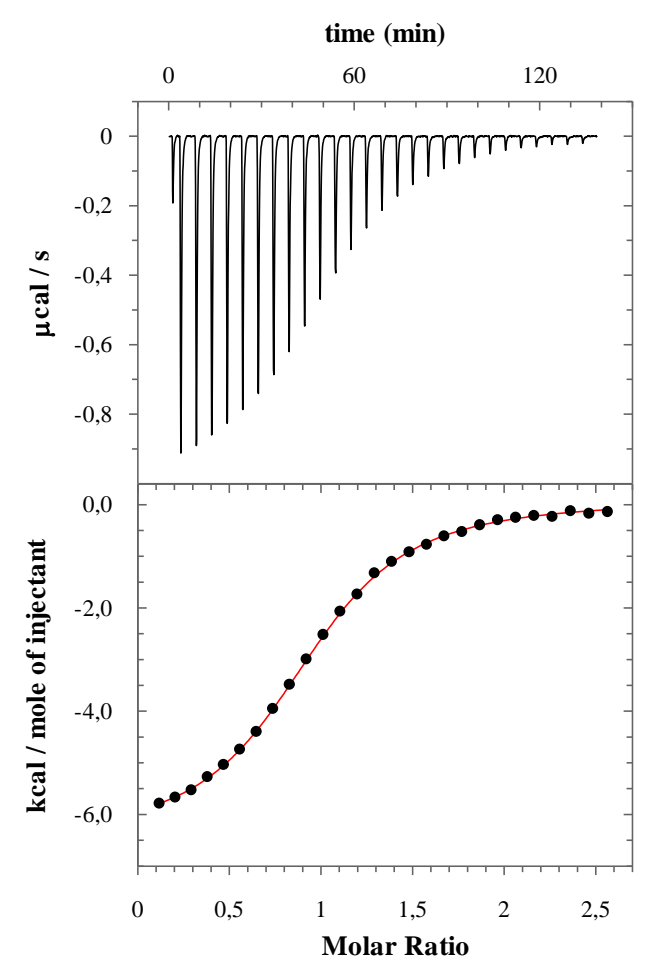

Figure 5. Microcalorimetric titration of butylsulfonate $(\mathrm{G})$ with pillar[5]arene $(\mathrm{H})$ in water at $25^{\circ} \mathrm{C}$. Top: Raw data for the 28 sequential injections $(10 \mu \mathrm{L}$ per injection) of a solution of $\mathrm{G}(0.5 \mathrm{mM})$ into a solution of $\mathrm{H}(0.04 \mathrm{mM})$. Bottom: "Net" heat effects obtained by subtracting the dilution heat from the reaction heat, which was fitted by computer simulation using the "one set of sites" binding model.

Table 2. Thermodynamic parameters obtained for host:guest complexes between pillararene and different alkylsulfonates.

\begin{tabular}{|c|c|c|c|c|}
\hline & $\mathbf{K}\left(\mathbf{M}^{-1}\right)$ & $\Delta \mathrm{G}^{0}\left(\mathrm{kcal} \mathrm{mol}^{-1}\right)$ & $\Delta \mathrm{H}^{0}\left(\mathrm{kcal} \mathrm{mol}^{-1}\right)$ & $\mathrm{TS}^{0}\left(\mathrm{kcal} \mathrm{mol}^{-1}\right)$ \\
\hline $\mathrm{C}_{8} \mathrm{SO}_{3}{ }^{-}$ & $(4.79 \pm 0.18) \times 10^{7}$ & -10.43 & $-8.90 \pm 0.01$ & 1.5 \\
\hline $\mathrm{C}_{6} \mathrm{SO}_{3}{ }^{-}$ & $(1.67 \pm 0.02) \times 10^{7}$ & -9.91 & $-8.86 \pm 0.01$ & 1.05 \\
\hline $\mathrm{C}_{5} \mathrm{SO}_{3}{ }^{-}$ & $(5.88 \pm 0.04) \times 10^{6}$ & -9.19 & $-8.70 \pm 0.01$ & 0.49 \\
\hline $\mathrm{C}_{4} \mathrm{SO}_{3}{ }^{-}$ & $(2.63 \pm 0.01) \times 10^{6}$ & -8.72 & $-6.60 \pm 0.01$ & 2.12 \\
\hline $\mathrm{C}_{3} \mathrm{SO}_{3}^{-}$ & $(7.22 \pm 0.02) \times 10^{3}$ & -5.24 & $-4.42 \pm 0.01$ & 0.82 \\
\hline
\end{tabular}

The results indicate that complexation is mainly enthalpy-driven $\left(\Delta \mathrm{H}^{0}=-(6.60 \pm 0.01)\right.$ $\mathrm{kcal} / \mathrm{mol})$ accompanied by favorable entropic changes $\left(\mathrm{T} \Delta \mathrm{S}^{0}=2.12 \mathrm{kcal} / \mathrm{mol}\right)$, this balance being more favorable to the enthalpic term with the others alkylsufonates. From the results of experiments performed between guests and other macrocycles, it is well known that noncovalent interactions, such as ionic, , and $\mathrm{C}-\mathrm{H} \cdots \pi$, contribute to the enthalpic changes, and that the conformational changes and desolvation effect contribute to the entropic changes [62]. For the entropic changes, the hydrophobic interactions, electrostatic attraction and dehydration processes give a positive contribution, while the loss of conformational degrees of freedom by the guest or the host gives a negative contribution. Therefore the thermodynamic parameters obtained suggest that electrostatic, $\pi-\pi$, and C$\mathrm{H} \cdots \pi$ interactions between aromatic ring and methyl group of alkylsulfonate and the 
electron rich cavity of pillararene should contribute to the favorable enthalpy. Simultaneously, the water molecules around the guest and the host are released into the aqueous bulk phase, and should be the main reason for the entropic gain. The binding constant obtained, $\mathrm{K}=(2.63 \pm 0.01) \times 10^{6} \mathrm{M}^{-1}$, is comparable with those reported for negatively charged pillararenes $[52,53,62,63]$ or calixarenes [64-66].

Experimental results reported in Table 2 show alkylsulfonate binding constants to be very sensitive to alkylsulfonate chain length with an increase of almost $10^{4}$ fold on going from propane to octanesulfonate. Quantitative analysis of these binding constants requires correction of binding constant for propanesulfonate. Because of its smaller value, experimental results were obtained in the presence of [Pillararene] $=0.25 \mathrm{mM}$ instead of [Pillararene] $=0.04 \mathrm{mM}$ used for other alkylsulfonates. Previous results from our group have shown that toluenesulfonate binding constant to pillararene decreases from $1.37 \times 10^{6} \mathrm{M}^{-1}$ to $3.18 \times 10^{4} \mathrm{M}^{-1}$ by increasing the host concentration from 0.01 to $0.1 \mathrm{mM}$ [53]. This is a consequence of the complexation of the counterions $\mathrm{BF}_{4}$ by the pillararene, which obstructs the entrance of the guest as well as the change of the net charge of the host. Extrapolation to alkylsulfonates implies that propanesulfonate binding constant of $1.86 \times 10^{5} \mathrm{M}^{-1}$ should be used for comparative proposes.

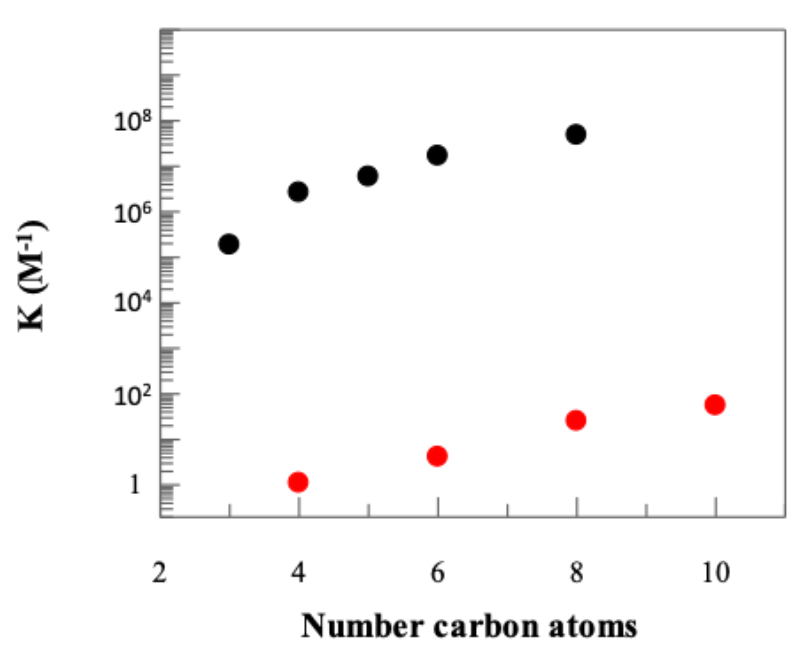

Figure 6. (•)Influence of alkyl chain length of alkylsulfonates on their binding constants to pillar[5]arene using a [pillararene] $=0.04 \mathrm{mM}$ at $25^{\circ} \mathrm{C}$. Value for propanesulfonate was extrapolated from $[$ host $]=0.25 \mathrm{mM}$ (see text). $(\bullet)$ Binding constants for alkylsulfonates to $\beta$-cyclodextrin taken from ref [67].

Figure 6 plots the dependence of the binding constant with the alkyl chain length and include similar results using $\beta$-cyclodextrin as receptor [67]. Quantitative analysis of the thermodynamic parameters involved in the complex formation between surfactant molecules and cyclodextrin can be simplified by considering the process divided into three stages:

(i) Dehydration of surfactant and cyclodextrin. This process is entropically favored given the strong structuring of water hydrating the exposed hydrophobic moiety of the surfactant and due to the geometrical constraints within the CD cavity. Water molecules structure themselves around the hydrophobic part of the surfactant, forming a strong hydrogen-bonded network. The amount of water molecules involved in the hydration scales linearly with the number of methylene units of the alkyl chain, thus the linear dependence on the surfactant chain length of the free energy of micellization, and similar phenomena which involve the removal of the alkyl chain from the aqueous environment. 
Inclusion of the surfactant in the CD's cavity. The inclusion occurs effectively with the inlet of the alkyl chain of surfactant in the hydrophobic cavity, with is internally stabilized by numerous Van der Waals interactions. The internal diameter of $\beta$-CD allows the loose accommodation of a methylene group.

(iii) Hydration of the inclusion complex. Finally, the water structure of the exposed part of the guest is restored and integrates the hydration shell of the complex [68].

Alkylsulfonate binding constants to $\beta$-CD increases with the number of methylene groups into the alkyl chain in a non-linear way. Binding constants for short alkyl chains and very large ones are smaller than expected. For small alkyl chains the occupancy of the cavity is not complete and, consequently, a small number of water molecules are expelled to the bulk. For large alkyl chains the binding constants are smaller than expected because of the allowance of the cyclodextrin cavity to accommodate 6-8 methylene groups.

Figure 6 shows that pillararene is a much effective receptor to alkylsulfonates than $\beta-C D$ by a factor of $10^{6}$. This effect should be ascribed to electrostatic interactions between the negative charge of the guest and the positive ones on the upper and lower rim of pillararene. Note that this interaction is not possible in the case of $\beta-C D$ as a receptor. The influence of the alkyl chain length on the binding constants to pillararene parallels that observed with $\beta-C D$ indicating that hydrophobic interactions are playing an important role in the recognition ability of pillararene.

Hydrophobic effects in pillararene recognition are responsible for the different location of the sulfonate group with respect to the positive upper or lower rim of the host. This different location is reflected by the complexation induced upfield effect observed in Figure 4-left for hydrogens in alpha position ( $\mathrm{Ha}$ ) to the sulfonate group. Electrostatic interaction in the host:guest complex will compel the sulfonate group close to the timethylammonium ones in such a way that the distance between the hydrogens Ha of the guest and the aromatic ring of the host keeps constant. However, experimental results indicate that this distance decrease for the following alkylsulfonates: $\mathrm{C}_{8} \mathrm{SO}_{3}{ }^{-} \mathrm{C}_{3} \mathrm{SO}_{3}{ }^{-}$ $>\mathrm{C}_{6} \mathrm{SO}_{3}{ }^{-}>\mathrm{C}_{5} \mathrm{SO}_{3} \approx \mathrm{C}_{4} \mathrm{SO}_{3}{ }^{-}$. X-ray crystal structure of 1,4-dipropoxypillar[5]arene confirmed that is a pentagon from the upper view and a pillar structure from the side view. The diameter of the internal cavity was $4.7 \AA$, which is similar to that of o-cyclodextrin, allows perfect inclusion of methylene chain [69]. The height of pillararene cavity, taken as the distance between the oxygen atoms in the upper and lower rims, is $5.5 \AA$, allowing accommodation of 4-5 methylene groups. It means that $\mathrm{C}_{5} \mathrm{SO}_{3}{ }^{-}$and $\mathrm{C}_{4} \mathrm{SO}_{3}$ - are deep included into the pillararene cavity in comparison to $\mathrm{C}_{8} \mathrm{SO}_{3}{ }^{-}$and $\mathrm{C}_{3} \mathrm{SO}_{3}{ }^{-}$. The smaller alkylsulfonate does not displace a large amount of water from the host cavity resulting in a small hydrophobic effect. On the other hand, three methylene groups of $\mathrm{C}_{8} \mathrm{SO}_{3}$ - will be outside the cavity. Their hydration in the host:guest complex will contribute unfavourably to its stability.

\section{Conclusions}

To sum up, we have demonstrated that alkylsulfonates with different chain length are effectively bound by a decacationic pillar[5]arene receptor in aqueous solution with binding constants in the micro/submicromolar range. The formation of the complexes is enthalpy and entropy driven suggesting that ionic, $\mathrm{C}-\mathrm{H} \cdots \pi$, van der Waals interaction along with hydrophobic effects contribute to the binding stability. The observed increase in the binding constants as the guest alkyl chain length increases provides strong evidence for the contribution of the hydrophobic effect for the recognition process. This view is supported by the structural NMR studies showing that hydrophobic alkyl chains are deeply included in aromatic cavity of the macrocyclic receptor. The results obtained herein suggest that cationic pillararene receptors are potentially strong binders for anionic 
and eventually zwitterionic lipids and therefore further studies addressing this class of natural molecules as guest should be considered due to the potential pharmaceutical applications of these macrocycles.

Author Contributions: For research articles with several authors, a short paragraph specifying their individual contributions must be provided. The following statements should be used "Conceptualization, L.G.R. and N.B.; methodology, L.G.R.; software, J.C.M.; validation, L.G.R. and N.B.; formal analysis, N.B.; investigation, B.G.G.; resources, B.G.G.; data curation, L.G.R. and N.B.; writingoriginal draft preparation, L.G.R.; writing - review and editing, N.B., J.C.M. and J.S.G.; visualization, J.C.M.; supervision, L.G.R.; project administration, L.G.R. and J.S.G.; funding acquisition, L.G.R. and J.S.G. All authors have read and agreed to the published version of the manuscript."

Funding: Financial support from the Ministerio de Economia y Competitividad of Spain (project CTQ2017-84354-P), Xunta de Galicia (GR 2007/085 and ED431C2018/42-GRC) and the European Regional Development Fund (ERDF) is gratefully acknowledged.

Institutional Review Board Statement: "Not applicable."

Informed Consent Statement: “Not applicable."

Conflicts of Interest: "The authors declare no conflict of interest. The funders had no role in the design of the study; in the collection, analyses, or interpretation of data; in the writing of the manuscript, or in the decision to publish the results".

\section{References}

1. Sijbesma, R. P.; Beijer, F. H.; Brunsveld, L.; Folmer, B. J.; Hirschberg, J. H.; Lange, R. F.; Lowe, J. K. L.; Meijer, E. W. Reversible polymers formed from self-complementary monomers using quadruple hydrogen bonding. Science 1997, 278, 1601-1604.

2. Hartgerink, J. D.; Beniash, E.; Stupp, S. I. Self-Assembly and Mineralization of Peptide-Amphiphile Nanofibers. Science 2001, 294, 1684-1688.

3. Zhang, W.; Jin, W.; Fukushima, T.; Saeki, A.; Seki, S.; Aida, T. Supramolecular Linear Heterojunction Composed of GraphiteLike Semiconducting Nanotubular Segments. Science 2011, 334, 340-343.

4. Wang, F.; Zhang, J.; Ding, X.; Dong, S.; Liu, M.; Zheng, B.; Li, S.; Wu, L.; Yu, Y.; Gibson, H. W.; Huang, F. Metal Coordination Mediated Reversible Conversion between Linear and Cross-Linked Supramolecular Polymers. Angew. Chem., Int. Ed. 2010, 49, 1090-1094.

5. Zhang, Z.; Luo, Y.; Chen, J.; Dong, S.; Yu, Y.; Ma, Z.; Huang, F. Formation of Linear Supramolecular Polymers That Is Driven

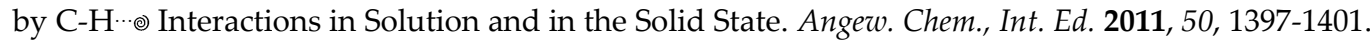

6. Wang, F.; Han, C.; He, C.; Zhou, Q.; Zhang, J.; Wang, C.; Li, N.; Huang, F. Self-Sorting Organization of Two Heteroditopic Monomers to Supramolecular Alternating Copolymers. J. Am. Chem. Soc. 2008, 130, 11254-11255.

7. Chen, K. -J.; Garcia, M. A.; Wang, H.; Tseng, H. -R. Supramolecular Nanoparticles for Molecular Diagnostics and Therapeutics. New York: Supramolecular Chemistry; John Wiley \& Sons Ltd; 2012.

8. Ma, X.; Zhao, Y. Biomedical applications of supramolecular systems based on host-guest interactions, Chem. Rev. 2015, 115, 7794-7839.

9. Rybtchinski, B. Adaptive Supramolecular Nanomaterials Based on Strong Noncovalent Interactions. ACS Nano 2011, 5, 67916818.

10. Lehn, J. M. Supramolecular Shemistry. Science 1993, 260, 1762-1763.

11. Stupp, S. I.; Lebonheur, V.; Walker, K.; Li, L. S.; Huggins, K. E.; Keser, M.; Amstutz, A. Supramolecular Materials: Self-Organized Nanostructures. Science 1997, 276, 384-389.

12. Oshovsky, G. V.; Reinhoudt, D. N.; Verboom, W. Supramolecular Chemistry in Water. Angew. Chem., Int. Ed. 2007, 46, 23662393.

13. Yan, X.; Wang, F.; Zheng, B.; Huang, F. Stimuli-responsive supramolecular polymeric materials. Chem. Soc. Rev. 2012, 41, 60426065.

14. Sambe, L.; Belal, K.; Stoffelbach, F.; Lyskawa, J.; Delattre, F.; Bria, M.; Sauvage, F. X.; Sliwa, M.; Humblot, V.; Charleux, B.; Cooke, G.; Woisel, P. Multi-stimuli responsive supramolecular diblock copolymers. Polym. Chem. 2014, 5, $1031-1036$.

15. Choudhury, S. D.; Barooah, N.; Aswal, V. K.; Pal, H.; Bhasikuttan, A. C.; Mohanty, J. Stimuli-responsive supramolecular micellar assemblies of cetylpyridinium chloride with cucurbit[5/7]urils. Soft Matter 2014, 10, 3485-3493.

16. Schaeffer, G.; Fuhr, O.; Fenske, D.; Lehn, J.-M. Self-Assembly of a Highly Organized, Hexameric Supramolecular Architecture: Formation, Structure and Properties. Chem.-Eur. J. 2014, 20, 179-186.

17. Bissantz, C.; Kuhn, B.; Stahl, M. A Medicinal Chemist's Guide to Molecular Interactions. J. Med. Chem. 2010, 53, 5061-5084.

18. Morra, G.; Genoni, A.; Neves, M. A. C.; Merz, K. M.; Colombo, G. Molecular Recognition and Drug-Lead Identification: What Can Molecular Simulations Tell Us?. Curr. Med. Chem. 2010, 17, 25-41. 
19. Zhang, M.; Yan, X.; Huang, F.; Gibson, H. W. Stimuli-Responsive Host-Guest Systems Based on the Recognition of Cryptands by Organic Guests. Acc. Chem. Res. 2014, 47, 1995-2005.

20. Kralij, M.; Tusek-Bozic, L.; Frkanec, L. Biomedical potentials of crown ethers: prospective antitumor agents. ChemMedChem 2008, 3, 1478-1492.

21. Goek, G. W.; Leevy, W. M.; Weber, M. E. Crown Ethers: Sensors for Ions and Molecular Scaffolds for Materials and Biological Models. Chem. Rev. 2004, 104, 2723-2750.

22. Hof, F. Host-guest chemistry that directly targets lysine methylation: synthetic host molecules as alternatives to bio-reagents. Chem. Commun. 2016, 52, 10093-10108.

23. Ramaiah, D.; Neelakandan, P. P.; Naira, A. K.; Aviraha, R. R. Functional cyclophanes: Promising hosts for optical biomolecular recognition. Chem. Soc. Rev. 2010, 39, 4158-4168.

24. Tan, N.-H.; Zhou, J. Plant Cyclopeptides. Chem. Rev. 2006, 106, 840-895.

25. Galan, M. C.; Dumy, P.; Renaudet, O. Multivalent glyco(cyclo)peptides. Chem. Soc. Rev. 2013, 42, 4599-4612.

26. Russo, A.; Aiello, C.; Grieco, P.; Marasco, D. Targeting "Undruggable" Proteins: Design of Synthetic Cyclopeptides. Curr. Med. Chem. 2016, 23, 748-762.

27. Davis, M. E.; Brester, M. E. Cyclodextrin-based pharmaceutics: past, present and future. Nat. Rev. Drug Discovery 2004, 3, 10231035.

28. Mellet, C. O.; Fernandez, J. M. G.; Benito, J. M. Cyclodextrin-based gene delivery systems. Chem. Soc. Rev. 2011, 40, 1586-1608.

29. Crini, G. Review: A History of Cyclodextrins. Chem. Rev. 2014, 114, 10940-10975.

30. Timmerman, P.; Verboom, W.; Reinhoudt, D. N. Resorcinarenes. Tetrahedron 1996, 52, 2663-2704.

31. Assaf, K. I.; Nau, W. M. Cucurbiturils: from synthesis to high-affinity binding and catalysis. Chem. Soc. Rev. 2015, 44, 394-418.

32. Lagona, J.; Mukhopadhyay, P.; Chakrabarti, S.; Isaacs, L. The Cucurbit[n]uril Family. Angew. Chem., Int. Ed. 2005, 44, 4844-4870.

33. Barrow, S. J.; Kasera, S.; Rowland, M. J.; Barrio, J.; Scherman, O. A. Cucurbituril-Based Molecular Recognition. Chem. Rev. 2015, 115, 12320-12406.

34. Kim, K.; Selvapalam, N.; Ko, Y. H.; Park, K. M.; Kim, D.; Kim, J. Functionalized cucurbiturils and their applications. Chem. Soc. Rev. 2007, 36, 267-279.

35. Diamond, D.; Mckervey, M. A. Calixarene-based sensing agents. Chem. Soc. Rev. 1996, 25, 15-24.

36. Ikeda, A.; Shinkai, S. Novel Cavity Design Using Calix[n]arene Skeletons: Toward Molecular Recognition and Metal Binding. Chem. Rev. 1997, 97, 1713-1734.

37. Böhmer, V. Calixarenes, Macrocycles with (Almost) Unlimited Possibilities. Angew. Chem., Int. Ed. Engl. 1995, 34, 713-745

38. Nimse, S. B.; Kim, T. Biological applications of functionalized calixarenes. Chem. Soc. Rev. 2013, 42, 366-386.

39. Sathiyajith, C. W.; Shaikh, R. R.; Han, Q.; Zhang, Y.; Meguellati, K.; Yang, Y-W. Biological and related applications of pillar[n]arenes. Chem. Commun. 2017, 53, 677-696

40. Ogoshi, T.; Kanai, S.; Fujinami, S.; Yamagishi, T.; Nakamoto, Y. para-Bridged Symmetrical Pillar[5]arenes: Their Lewis Acid Catalyzed Synthesis and Host-Guest Property. J. Am. Chem. Soc. 2008, 130, 5022-5023.

41. Nierengarten, I.; Guerra, S.; Holler, M.; Karmazin-Brelot, L.; Barbera, J.; Deschenaux, R.; Nierengarten, J.-F. Macrocyclic Effects in the Mesomorphic Properties of Liquid-Crystalline Pillar[5]- and Pillar[6]arenes. Eur. J. Org. Chem. 2013, 3675-3684.

42. Li, C. Pillararene-based supramolecular polymers: from molecular recognition to polymeric aggregates. Chem. Commun. 2014, $50,12420-12433$.

43. Wang, K.; Wang, C. Y.; Zhang, Y.; Zhang, S. X. A.; Yang, B.; Yang, Y. W. Ditopic pillar[5]arene-based fluorescence enhancement material mediated by [c2]daisy chain formation. Chem. Commun. 2014, 50, 9458-9461.

44. Hua, B.; Shao, L.; Yu, G.; Huang, F. Fluorescence indicator displacement detection based on pillar[5]arene-assisted dye deprotonation. Chem. Commun. 2016, 52, 10016-10019.

45. Ogoshi, T.; Kayama, H.; Yamafuji, D.; Aoki, T.; Yamagishi, T.-A. Supramolecular polymers with alternating pillar[5]arene and pillar[6]arene units from a highly selective multiple host-guest complexation system and monofunctionalized pillar[6]arene. Chem. Sci. 2012, 3, 3221-3226.

46. Duan, Q.; Cao, Y.; Li, Y.; Hu, X.; Xiao, T.; Lin, C.; Pan, Y.; Wang, L. pH-Responsive Supramolecular Vesicles Based on WaterSoluble Pillar[6]arene and Ferrocene Derivative for Drug Delivery. J. Am. Chem. Soc. 2013, 135, 10542-10549.

47. Si, W.; Xin, P.; Li, Z.-T.; Hou, J.-L. Tubular Unimolecular Transmembrane Channels: Construction Strategy and Transport Activities. Acc. Chem. Res. 2015, 48, 1612-1619.

48. Yu, G.; Ma, Y.; Han, C.; Yao, Y.; Tang, G.; Mao, Z.; Gao, C.; Huang, F. A Sugar-Functionalized Amphiphilic Pillar[5]arene: Synthesis, Self-Assembly in Water, and Application in Bacterial Cell Agglutination. J. Am. Chem. Soc. 2013, 135, 10310-10313.

49. Zhang, Z.; Zhao, Q.; Yuan, J.; Antonietti, M.; Huang, F. A hybrid porous material from a pillar[5]arene and a poly(ionic liquid): selective adsorption of n-alkylene diols. Chem. Commun. 2014, 50, 2595-2597.

50. Ogoshi, T.; Yamagishi, T.; Nakamoto, Y. Pillar-shaped macrocyclic hosts pillar[n]arenes: new key players for supramolecular chemistry. Chem. Rev. 2016, 116, 7937-8002.

51. Strutt, N. L.; Zhang, H.; Schneebeli, S. T.; Stoddart, J. F. Amino-Functionalized Pillar[5]arene. Chem. -Eur. J. 2014, 20, 1099611004.

52. Gómez, B.; Francisco, V.; Fernández-Nieto, F.; Garcia-Rio, L.; Martín-Pastor, M.; Paleo, M. R.; Sardina, F. J. Host-Guest Chemistry of a Water-Soluble Pillar[5]arene: Evidence for an Ionic-Exchange Recognition Process and Different Complexation Modes. Chem. Eur. J. 2014, 20, 12123-12132. 
53. Gómez, B.; Francisco, V.; Montecinos, R.; Garcia-Rio, L. Investigation of the binding modes of a positively charged pillar[5]arene: internal and external guest complexation. Org. Biomol. Chem. 2017, 15, 911-919.

54. Liz, D. G.; Manfredi, A. M.; Medeiros, M.; Montecinos, R.; Gómez, B.; Garcia-Rio, L.; Nome, F. Supramolecular phosphate transfer catalysis by pillar[5]arene. Chem. Commun. 2016, 52, 3167-3170.

55. Wanderlind, E. H.; Liz, D. G.; Gerola, A. P.; Affeldt, R. F.; Nascimento, V.; Bretanha, L. C.; Montecinos, R.; Garcia-Rio, L.; Fiedler, H. D.; Nome, F. Imidazole-functionalized pillar[5]arenes: highly reactive and selective supramolecular artificial enzymes. ACS Catal. 2018, 8, 3343-3347.

56. Silveira, E. V.; Nascimento, V.; Wanderlind, E. H.; Affeldt, R. F.; Micke, G. A.; Garcia-Rio, L.; Nome, F. Inhibitory and cooperative effects regulated by $\mathrm{pH}$ in host-guest complexation between cationic pillar[5]arene and reactive 2-carboxyphthalanilic acid. J. Org. Chem. 2019, 84, 9684-9692.

57. Montes-Garcia, V.; Fernández-López, C.; Gómez, B.; Pérez-Juste, I.; Garcia-Rio, L.; Liz-Marzán, L. M.; Pérez-Juste, J.; PastorizaSantos, I. Pillar[5]arene-mediated synthesis of gold nanoparticles: size control and sensing capabilities. Chem. Eur. J. 2014, 20, 8404-8409.

58. Montes-Garcia, V.; Gómez, B.; Martínez-Solís, D.; Taboada, J. M.; Jiménez-Otero, N.; Uña-Alvarez, J.; Obelleiro, F.; Garcia-Rio, L.; Pérez-Juste, J.; Pastoriza-Santos, I. Pillar[5]arene-based supramolecular plasmonic thin films for label-free, quantitative and multiplex SERS detection. ACS Appl. Mater. Interfaces 2017, 9, 26372-26382.

59. Barrán-Berdón, A. L.; Martínez-Negro, M.; Garcia-Rio, L.; Domènech, O.; Tros de Ilarduya, C.; Aicart, E.; Junquera, E. Biophysical study of gene nanocarriers formed by anionic/zwitterionic mixed lipids and pillar[5]arene policationic macrocycles. J. Mat. Chem. B 2017, 5, 3122-3131.

60. Zhang, H.; Liu, Z.; Zhao, Y. Pillararene-based self-assembled amphiphiles. Chem. Soc. Rev. 2018, 47, 5491-5528.

61. Ma, Y.; Ji, X.; Xiang, F.; Chi, X.; Han, C.; He, J.; Abliz, Z.; Chen, W.; Huang, F. A cationic water-soluble pillar[5]arene: synthesis and host-guest complexation with sodium 1-octanesulfonate. Chem. Commun. 2011, 47, 12340-12342.

62. Douteau-Guével, N.; Coleman, A. W.; Morel, J.-P.; Morel-Desrosiers, N. Complexation of the basic amino acids lysine and arginine by three sulfonatocalix[n]arenes $(n=4,6$ and 8) in water: microcalorimetric determination of the Gibbs energies, enthalpies and entropies of complexation. J. Chem. Soc. Perkin Trans. 2 1999, 629-633.

63. Yu, G.; Zhou, X.; Zhang, Z.; Han, C.; Mao, Z.; Gao, C.; Huang, F. Pillar[6]arene/Paraquat Molecular Recognition in Water: High Binding Strength, pH-Responsiveness, and Application in Controllable Self-Assembly, Controlled Release, and Treatment of Paraquat Poisoning. J. Am. Chem. Soc. 2012, 134, 19489-19497.

64. Francisco, V.; Basilio, N.; Garcia-Rio, L. Counterion Exchange as a Decisive Factor in the Formation of Host:Guest Complexes by p-Sulfonatocalix[4]arene. J. Phys. Chem. B 2012, 116, 5308-5315.

65. Arena, G.; Gentile, S.; Gulino, F. G.; Sciotto, D.; Sgarlata, C. Water-soluble pentasulfonatocalix[5]arene: selective recognition of ditopic trimethylammonium cations by a triple non-covalent interaction. Tetrahedron Lett. 2004, 45, 7091-7094.

66. Guo, D.-S.; Wang, L.-H.; Liu, Y. Highly Effective Binding of Methyl Viologen Dication and Its Radical Cation by p-Sulfonatocalix[4,5]arenes. J. Org. Chem. 2007, 72, 7775-7778.

67. Cepeda, M.; Daviña, R.; García-Río, L.; Parajó, M. Cyclodextrin-surfactant binding constant as driven force for uncomplexed cyclodextrin in equilibrium with micellar systems. Chem. Phys. Lett. 2010, 499, 70-74.

68. Araujo, L. S. S.; Lazzara, G.; Chiappisi, L. Cyclodextrin/surfactant inclusion complexex: An integrated view of their thermodynamic and structural properties. Adv. Coll. Int. Sci. 2021, 289, 102375-102386.

69. Xue, M.; Yang, Y.; Chi, X.; Zhang, Z.; Huang, F. Pillararenes, A New Class of Macrocycles for Supramolecular Chemistry. Acc. Chem. Res. 2012, 45, 1294-1308. 